\title{
ABC AUTISMO: Um aplicativo móvel para auxiliar na alfabetização de crianças com autismo baseado no Programa TEACCH
}

\author{
Ezequiel B. Farias, Leandro W. C. Silva, Mônica X. C. Cunha \\ Instituto Federal de Educação, Ciência e Tecnologia de Alagoas (IFAL) - Campus \\ Maceió - Maceió - AL - Brasil \\ ezequiel_maceio@yahoo.com.br, leandrowcs@hotmail.com, mxcc@hotmail.com
}

\begin{abstract}
Modern information technologies have supported a number of areas, among them education and health, in order to deliver improvements in administrative processes and quality of life. This article presents the trajectory of development and validation of a mobile app, titled Autism ABC, whose main aid in the process of teaching children with autism and hence serve as a supporting tool in the treatment and education of these individuals function. The application adopts assumptions TEACCH program. Children, parents and professionals an association attended the validation step. The results attest to the tool alignment with the TEACCH and a self-explanatory interface.
\end{abstract}

Resumo. As modernas tecnologias da informação têm apoiado inúmeras áreas, dentre elas a educação e a saúde, com o intuito de proporcionar uma melhoria nos processos administrativos e na qualidade de vida das pessoas. Este artigo apresenta a trajetória de desenvolvimento e validação de um aplicativo móvel, intitulado $\mathrm{ABC}$ Autismo, que tem como principal função auxiliar no processo de alfabetização de crianças com autismo e, consequentemente, servir como ferramenta de apoio no tratamento e educação destes indivíduos. $\mathrm{O}$ aplicativo adota premissas do programa TEACCH. Crianças, pais e profissionais de uma associação participaram da etapa de validação. Os resultados atestaram o alinhamento da ferramenta com o TEACCH e uma interface autoexplicativa. 


\section{INTRODUÇÃO}

O autismo é um transtorno invasivo do desenvolvimento que engloba déficits qualitativos na interação social e na comunicação, padrões de comportamento repetitivos e estereotipados e um repertório restrito de interesses e atividades [RAPIN 1991]. Apesar do termo autismo não ser novo e de existirem uma multiplicidade de estudos reconhecendo que há uma causa biológica para a patologia [CAPUCHA 2008], ainda existem muitas questões que não foram devidamente respondidas. Ainda não se tem a confirmação de todos os fatores que originam o autismo, apesar de todos os avanços alcançados na área ainda não se sabe exatamente como as anormalidades genéticas oriundas da síndrome evoluem para quadros graves de comprometimento cognitivo [GUPTA; STATE 2006].

O que se sabe de concreto é que o autismo é um transtorno do desenvolvimento de causas neurobiológicas, definido de acordo com critérios eminentemente clínicos [SCHWARTZMAN 2011]. Para Capucha (2008), as Perturbações do Espectro do Autismo (PEA) consistem num distúrbio severo do neurodesenvolvimento que se manifesta através de dificuldades muito específicas da comunicação e da interação social associadas as dificuldades em utilizar a imaginação, em aceitar alterações de rotinas e à exibição de comportamentos estereotipados e restritos, que persistem ao longo da vida, podendo coexistir com outras patologias.

Ainda não existem exames clínicos que possam diagnosticar efetivamente o autismo, sendo este obtido mediante observação comportamental [COELHO 2006]. As escalas diagnósticas que vem sendo utilizadas mais efetivamente para a identificação do autismo são o DSM-IV-TR e o CID - 10, que baseiam suas avaliações em três critérios essenciais: a) déficits qualitativos na interação social; b) atraso e déficit de linguagem e comunicação; c) comportamentos, atividades ou interesses restritivos, repetitivos e estereotipados [SANTOS 2009].

O autismo não tem cura, além disso, não existe um remédio exclusivo para combater os sintomas do espectro em sua completude, o que se tem são medicamentos isolados que combatem sintomas específicos. No mesmo contexto as manifestações das debilidades inerentes ao autismo prejudicam e muito a aprendizagem destes indivíduos, uma vez que se refletem em características como: facilidade de distração, dificuldades básicas de organização, de sequenciamento de atividades, do entendimento de abstrações, dificuldade em interagir com outras pessoas, dentre outras, que acabam por exigir uma adaptabilidade das ações com o intuito de promover um aprendizado efetivo.

Apesar de se tratarem de indivíduos com necessidades especiais, alguns com considerável déficit cognitivo, o tratamento multidisciplinar baseado em metodologias amplamente testadas e mundialmente utilizadas, promovem resultados bastante animadores, favorecendo uma compreensão de mundo a essas crianças que muito colaboram com a sua alfabetização [ORRÚ 2009].

Dentre as abordagens mais utilizadas para o tratamento de pessoas com autismo destaca-se o Tratamento e Educação para Autistas e Crianças com Déficits relacionados com a Comunicação (TEACCH), um programa criado em 1964, na Universidade da Carolina do Norte (EUA), por Eric Schoppler e colaboradores, que abrange as esferas de atendimento educacional e clínico, em uma prática psicoeducativa, tornando-o por definição, uma abordagem transdisciplinar [KNEE; SAMPAIO; ATHERINO 2009].

O programa TEACCH trabalha essencialmente com a estruturação do tempo, atividades, materiais e ambientes utilizados pela criança visando compensar os déficits 
característicos do espectro do autismo e proporcionar ganhos significativos para o convívio social. Trata-se de um programa mundialmente utilizado para favorecer o processo de alfabetização de crianças com autismo. Este programa compreende 04 níveis de intervenção, chamados níveis de trabalho, incrementados gradualmente em complexidade que visam de uma forma adaptada ensinar noções básicas relacionadas à alfabetização.

As atividades propostas pelo programa acompanham o nível de desenvolvimento da cada criança autista, devendo ser executadas mediante a transposição de elementos do lado esquerdo, denominado área de armazenamento, para o lado direito da tela, denominado área de execução. O programa também recomenda que cada atividade da sequência seja repetida com a criança até que ela internalize efetivamente as características que a mesma trabalha.

A adaptabilidade do processo de ensino por meio da confecção de atividades manuais de acordo com o nível cognitivo de cada indivíduo, de forma alinhada com o que propõe o Programa TEACCH, acaba por exigir esforços significativos relacionados aos custos envolvidos com a aquisição, adaptação de materiais para criação das tarefas, além do tempo dedicado ao processo que poderia ser melhor aproveitado para o acompanhamento do tratamento.

Cientes de que a tecnologia tem se mostrado benéfica em muitos setores, inclusive na saúde e educação, uma vez que propicia a automatização de diversas tarefas e facilita a contabilização de resultados provenientes dos tratamentos, acredita-se que a utilização de recursos computacionais venha a gerar impactos positivos no tratamento das pessoas com autismo, uma vez que ela possui caráter cada vez mais ubíquo no dia-a-dia da sociedade.

Nesta vertente surgiu o aplicativo móvel ABC Autismo, que automatiza o processo de elaboração de atividades educacionais, utilizando as premissas do Programa TEACCH, com interfaces amigáveis e autoexplicativas, como requer uma ferramenta para este público alvo. As próximas seções do artigo estão organizadas da seguinte forma: a seção 2 apresenta o procedimento metodológico adotado na pesquisa, a seção 3 apresenta aspectos do desenvolvimento do aplicativo $\mathrm{ABC}$ Autismo, a seção 4 apresenta a validação da ferramenta junto a crianças com autismo que são atendidas em uma associação e a seção 5 apresenta as conclusões.

\section{PROCEDIMENTO METODOLÓGICO}

Todo um caminho precisou ser trilhado para se atingir o objetivo de criar um aplicativo móvel que pudesse beneficiar de uma forma ampla o tratamento das crianças com autismo. Inicialmente foi necessário estabelecer marcos com o intuito de definir quais as etapas necessárias para a construção de uma ferramenta eficiente e eficaz. O primeiro passo delineado foi compreender as particularidades do universo autista. O conhecimento dos sintomas, características do espectro do autismo, especificidades, peculiaridades, variantes e demais detalhes deste universo foi fundamental, afinal de contas todo software precisa se adequar às reais necessidades de seu público alvo, que neste caso em particular são as crianças com autismo.

Inicialmente foi realizado um vasto levantamento bibliográfico sobre o assunto, que permitiu a equipe envolvida com o projeto, obter características que futuramente comporiam funcionalidades presentes no aplicativo. Além disso, foi realizada uma pesquisa exploratória, de cunho qualitativo, mediante visitas a uma associação que atende crianças com autismo em Maceió, de caráter assistencial e sem fins lucrativos, que utiliza o Programa TEACCH como base em seus tratamentos. 
A referida associação permitiu, mediante autorização dos pais, o acompanhamento de alguns dos tratamentos possibilitando a observação da aplicação na prática da abordagem TEACCH. Durante a pesquisa de campo, uma série de entrevistas com a equipe multidisciplinar de profissionais que atendem as crianças na associação foi realizada com o intuito de levantar os requisitos iniciais relacionados aos procedimentos utilizados, especialmente aqueles relacionados ao programa TEACCH. Muitos desses dados levantados foram registrados na forma de relatório e deram suporte para a execução de todo um processo de especificação do aplicativo com o desenvolvimento dos modelos de telas, diagramação dos elementos e documentação, visando explicitar todas as funcionalidades necessárias para compor o aplicativo. Neste processo, foram utilizadas ferramentas que auxiliaram bastante na construção dos esquemas e protótipos de tela, como o Evolus Pencil para elaboração dos modelos de tela e o Astah Comunnity para a diagramação do projeto.

Após captar as limitações impostas ao sistema e definidas as funcionalidades mais críticas, outro levantamento foi realizado com o intuito de definir qual a linguagem de programação a ser utilizada para o desenvolvimento da ferramenta. Neste processo a linguagem Java, voltada para sistemas operacionais Android, foi escolhida. Dentre os fatores que mais influenciaram na escolha estão a sua portabilidade, pelo fato de ser uma linguagem totalmente aberta, o que sem dúvida beneficiará qualquer tentativa de adaptação do aplicativo para outras plataformas, além das próprias características da ferramenta, voltada para dispositivos móveis.

Paralelamente a estes esforços, foi definida a metodologia de desenvolvimento a ser aplicada no processo de codificação do aplicativo. A que melhor se adequou ao perfil do projeto foi a Scrum, que determina que o processo de codificação seja dividido em Sprints, baseadas diretamente em estórias de usuários elaboradas em conjunto com os profissionais entendedores do programa TEACCH base para o aplicativo. Cada uma das Sprints teve um prazo previamente estabelecido para entrega e foram minunciosamente revisadas permitindo melhorias constantes na implementação de funcionalidades para a ferramenta. Por fim iniciou-se o processo de codificação da ferramenta que permitiu elaborar um mínimo produto viável, chamado de versão beta do aplicativo $\mathrm{ABC}$ Autismo, que possibilitou iniciar o processo de validação (última fase do desenvolvimento), através da utilização do aplicativo pelas crianças que será explanado em seções posteriores.

\section{PROCESSO DE DESENVOLVIMENTO DO APLICATIVO ABC AUTISMO}

Através da ampla utilização dos conhecimentos adquiridos com a área de sistemas de informação a intenção foi criar um programa de computador lúdico e divertido a fim de contribuir com o processo de alfabetização de crianças com autismo ou com défices relacionados ao aprendizado. Como condição fundamental, a ferramenta precisaria incorporar algumas das premissas do programa TEACCH, principalmente as recomendações relacionadas à estruturação e adaptação das atividades utilizadas para o processo alfabetizador de crianças com autismo. O objetivo que norteou todo o processo de desenvolvimento foi a criação de uma ferramenta que futuramente auxiliasse e consequentemente agregasse valor ao tratamento de crianças com autismo.

Como requisito de desenvolvimento estabeleceu-se que o aplicativo em questão utilizaria uma plataforma móvel, sendo implementado inicialmente para Tablets com o sistema operacional Android. Toda implementação foi realizada de forma a abrir espaço para possíveis adequações que qualifiquem o aplicativo a rodar em outras plataformas. O processo de desenvolvimento abarcou inicialmente a prototipação do aplicativo, onde foram elaborados os modelos de tela com o intuito de representar o mais fidedignamente possível as 
funcionalidades e interfaces que foram definidas para o aplicativo, bem como prover uma orientação para que o designer pudesse elaborar as interfaces que comporiam a ferramenta. $\mathrm{O}$ diagrama de casos de uso, o diagrama de classes e alguns protótipos de tela do aplicativo ABC Autismo seguem a descrição apresentada em Farias e Cunha (2013). O presente trabalho apresenta a versão beta do aplicativo, que já se encontra disponível no Google Play. Cada atividade descrita a seguir pertencente a um dos quatro níveis de trabalho do programa TEACCH. Também serão abordadas algumas das funcionalidades definidas para a ferramenta sempre as relacionando às recomendações do programa TEACCH, que serviu como base para o aplicativo.

O modelo de tela em evidência na Figura 1 está relacionado ao primeiro nível de trabalho do programa TEACCH delineado para o aplicativo. As características incorporadas ao referido protótipo tiveram que ser adaptadas uma vez que não foi possível retratar toda a dinâmica determinada pelo programa para este nível. Por abarcar exclusivamente atividades que estimulam a ação de transposição de objetos concretos das mais variadas formas e tamanhos possíveis, este nível inicial foi criado na perspectiva do aplicativo exclusivamente por atividades de transposição de imagens. Acredita-se que as habilidades trabalhadas neste nível não foram comprometidas, pelo fato de trabalharem também a questão da coordenação motora, porém com outro tipo de dinâmica. A capacidade de arrastar elementos, agora como função predominante, foi amplamente explorada uma vez que possibilitou, através de um plano estratégico, desenvolver uma dinâmica que preconizou estimular a criança de diversas formas.

Além da diversidade de cores e objetos ter sido potencializada nesta nova abordagem, foi possível também diversificar os formatos de resposta aceitáveis dentro das áreas correspondentes. A dinâmica utilizada para automaticamente diminuir a área de resposta na medida em que a criança vai obtendo êxito na execução das exigências pertinentes a atividade, potencializa gradativamente a sua coordenação motora, provendo assim estímulos das mais variadas formas e perspectivas possíveis. É importante frisar que o contato da criança com o objeto concreto, realizado na forma convencional do Programa TEACCH é fundamental e de maneira nenhuma deve ser deixado de lado no processo de tratamento da criança. A nova abordagem apresentada pelo aplicativo ABC Autismo é apenas um complemento a toda a dinâmica utilizada e sem dúvida vem para somar no processo de intervenção com a criança.

\section{Figura 1 - Tela de atividade do nível 1 no aplicativo ABC Autismo.}

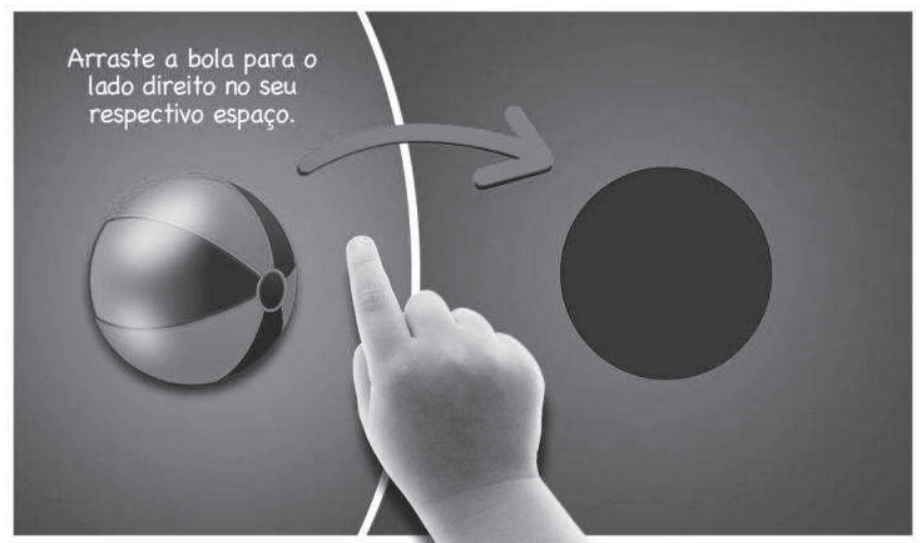

Fonte: Aplicativo ABC Autismo.

Dentro dos modelos de tela que compõem o Nível 2 de trabalho do TEACCH, apresentados na Figura 2, uma questão colocada dentro do enfoque para análise está relacionada à aleatoriedade de apresentação dos elementos por execução de atividade. 
Atualmente há uma recomendação do TEACCH para que sejam modificadas as ordens de posicionamento dos elementos da área de armazenamento, para evitar assim que a criança decore uma ordem possível de execução da atividade e possa realmente aprender a diferenciar os tamanhos, cores e formas existentes nos elementos apresentados. Visando atender a esta recomendação, dentro da lógica pensada para o aplicativo, foram incorporados mecanismos que garantissem a aleatoriedade de apresentação dos elementos a cada execução de uma atividade específica, o que proporcionou um maior dinamismo a todo o processo.

Dentro da mesma ótica outra característica importante do TEACCH contemplada pelo aplicativo correlaciona-se diretamente ao fato do profissional não permitir que a criança coloque um elemento em um campo de resposta inválido. Esta recomendação, denominada aprendizagem sem erro, visa auxiliar a criança a perceber o que é possível ou não dentro de suas ações no ato de execução da atividade. Em nível de funcionalidade, os campos de reposta das atividades no aplicativo estão todos validados, não permitindo assim a efetivação de respostas erradas. Além disso, todos os campos estão configurados de tal forma que acionem dicas de acordo com o número de erros da criança dentro da atividade. Estas características não são exclusivas apenas do nível 2 , sendo distribuídas por todos os níveis de atividades existentes, porém com um certo grau de especificidade.

Figura 2 - Tela de atividade do nível 2 no aplicativo ABC Autismo.

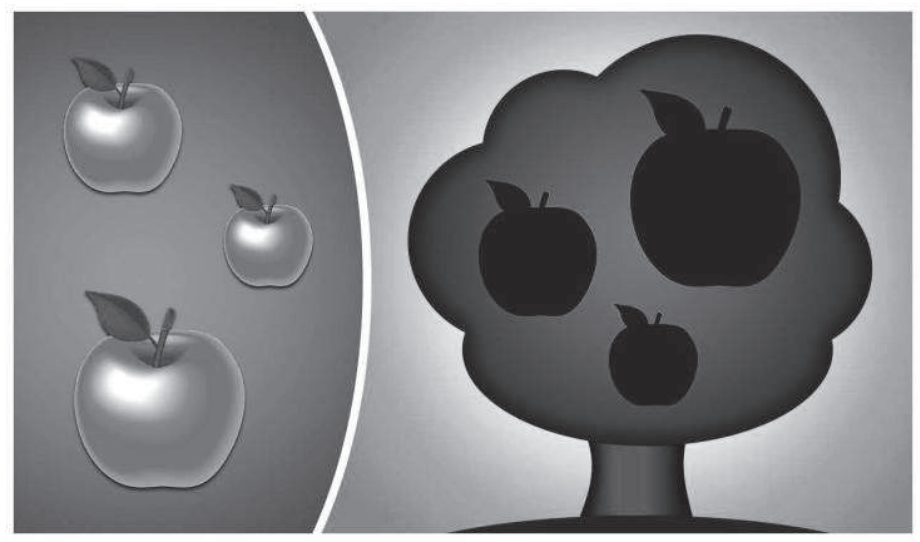

Fonte: Aplicativo ABC Autismo.

Os modelos de tela que compõem o Nível 3 seguiram a mesma estrutura dos níveis anteriores, e tiveram a mesma base funcional havendo apenas o acréscimo de algumas novas funcionalidades necessárias para a dinâmica apresentada pelo nível. Como explicado em seções anteriores o objetivo do nível é de ensinar a criança quais as diversas representações existentes para um mesmo elemento (sombra, figura, desenho, foto), características exclusivas de cada elemento ou categoria, ações e demais especificidades que complementam todas as habilidades estimuladas nos níveis anteriores.

Há uma quantidade significativa de atividades de quebra-cabeça neste nível, que procuram desenvolver a ideia do todo e das partes, além de múltiplas atividades de pareamento, sequenciamento, dentre outras. No Programa TEACCH há uma recomendação peculiar para as atividades de quebra-cabeça, aconselha-se que os elementos utilizados a princípio sejam os mais simples possíveis, sendo que os cortes realizados apresentem um caminho unidirecional, e a medida que o êxito da criança for sendo registrado novas atividades sejam apresentadas variando em complexidade da imagem em termos de riqueza de detalhes e cortes. Com o intuito de atender a este requisito toda uma sequência de cortes foi delineada para as imagens, partindo de uma estrutura de corte simples e geométrica, como a 
divisão de figuras em duas partes iguais orientadas tanto na horizontal como na vertical, até cortes mais complexos com formatos e dimensões diversas e multidirecionadas. Para facilitar o entendimento a Figura 3 ilustra um modelo de quebra cabeças de nível avançado pertencente ao aplicativo.

Figura 3 - Tela de atividade do nível 3 no aplicativo ABC Autismo.

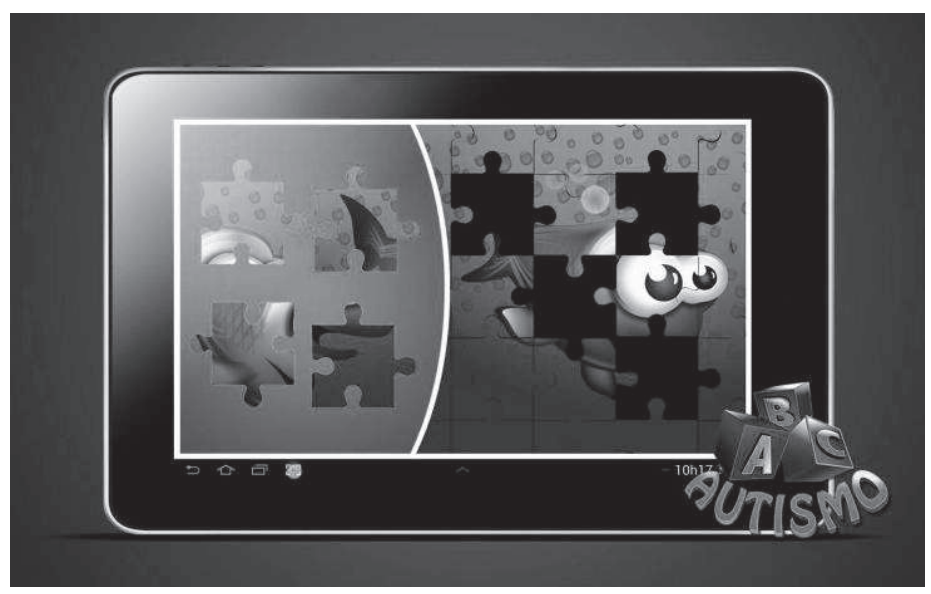

Fonte: Aplicativo ABC Autismo.

O processo de design dos modelos de tela também envolveu o último nível de trabalho do TEACCH, Nível 4, incorporando novas características ao modelo. Por ser um nível que abrange basicamente atividades de letramento, uma diversidade de dicas se torna necessária para uma efetiva aplicação e consequentemente obtenção dos melhores resultados. Como na abordagem manual, pretendeu-se dentro do processo contemplar também a derivação das atividades como ferramenta para a variabilidade do processo alfabetizatório.

Foram definidas uma série de dicas dentro da dinâmica de cada atividade, com utilização de margens coloridas para cada elemento, o uso das iniciais de cada palavra na área de resposta, preenchimento parcial de cada atividade, dentre outras. Todas estas características pertencentes ao Programa TEACCH puderam ser transferidas para o aplicativo sem qualquer tipo de perda ou prejuízo.

Aliadas aos tipos de ajuda supracitados foram determinadas outras formas de ação que pudessem ser disparadas dentro da atividade com o intuito de estimular a criança no processo de identificação da resposta correta. Estas dicas dinâmicas sem duvida agregaram muito ao processo e em alguns casos complementaram o trabalho dos profissionais uma vez que estabeleceram novas formas de chamar a atenção da criança. O parâmetro para ativação destas dicas, utilizado também nos níveis anteriores, foi o número de erros da criança dentro da atividade e boa parte das dicas pensadas para os outros níveis pôde ser reaproveitada no referido nível. Ações como o piscar de uma margem, de uma letra, de uma imagem, o surgimento de uma resposta com um tempo preestabelecido para visualização são apenas algumas das possibilidades de dicas definidas para o nível 4 . A Figura 4 apresenta um modelo de tela do nível 4. 
Figura 4 - Tela de atividade do nível 4 no aplicativo ABC Autismo.

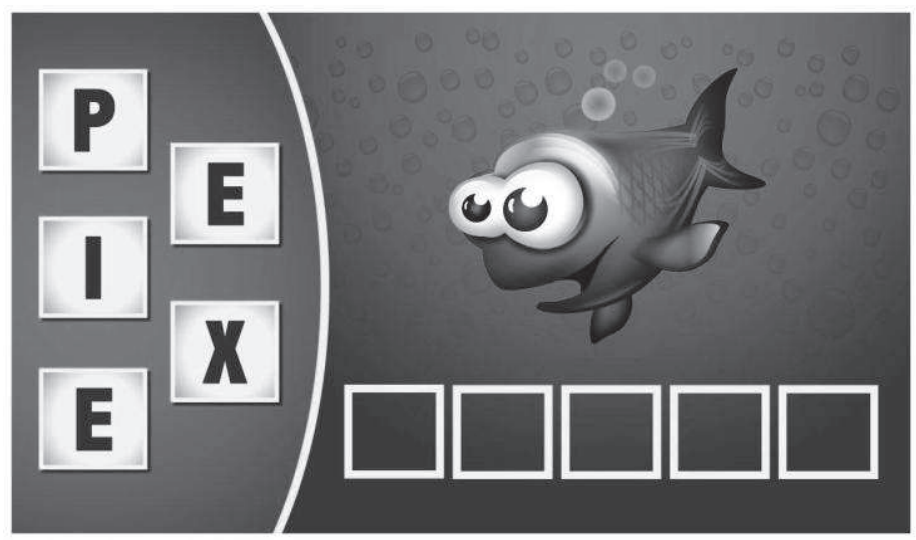

Fonte: Aplicativo ABC Autismo.

\section{VALIDAÇÃO DO APLICATIVO ABC AUTISMO}

Objetivando uma validação mais efetiva da ferramenta desenvolvida, se tornou necessário legitimar todas as funcionalidades pensadas para o aplicativo por meio da sua utilização pelo público alvo. Com esse intuito a forma de avaliação estabelecida para a versão beta do aplicativo ABC Autismo contemplou a observação das crianças utilizando o aplicativo durante os tratamentos dentro da associação parceira do estudo. Cabe ressaltar que todo o processo de validação foi autorizado tanto pela diretoria da associação quanto pelos pais das crianças que participaram dos testes.

Para averiguação das crianças utilizando a ferramenta estabeleceu-se que as mesmas seriam organizadas em dois grupos: as que apresentam linguagem verbal, que normalmente possuem um nível mais avançado de desenvolvimento cognitivo, e as que não apresentam linguagem verbal e se encontram nos níveis iniciais do tratamento. O teste da ferramenta com o público alvo se propôs a averiguar todos os 04 níveis de trabalho da abordagem TEACCH delineados no aplicativo ABC Autismo. As Tabelas 1 e 2 abordam respectivamente a distribuição da amostra quanto à presença ou ausência de linguagem verbal bem como a quantidade de crianças por nível TEACCH avaliado.

Tabela 01 - Distribuição das crianças participantes da pesquisa de acordo com a faixa etária e ausência/presença de linguagem verbal.

\begin{tabular}{c|c|c}
\hline Faixa Etária & Linguagem Verbal & $\begin{array}{c}\text { Sem Ling. } \\
\text { Verbal }\end{array}$ \\
\hline $4-6$ & 4 & 6 \\
\hline $7-10$ & 4 & 2 \\
\hline $11-13$ & 4 & 1 \\
\hline TOTAL & $\mathbf{1 2}$ & $\mathbf{9}$ \\
\hline
\end{tabular}

Fonte: Dados da Pesquisa. 


\section{Tabela 02 - Distribuição das crianças participantes da pesquisa de acordo com o nível TEACCH.}

\begin{tabular}{c|c}
\hline Nível TEACCH & $\begin{array}{c}\text { Quantidade de } \\
\text { crianças }\end{array}$ \\
\hline 1 & 4 \\
\hline 2 & 3 \\
\hline 3 & 5 \\
\hline 4 & 9 \\
\hline TOTAL & $\mathbf{2 1}$ \\
\hline
\end{tabular}

Fonte: Dados da Pesquisa.

Entre os pré-requisitos para realização dos testes estava a observância do nível de desenvolvimento de cada criança que só poderia executar atividades compatíveis com o mesmo. Os próprios terapeutas da associação ajudaram os pesquisadores indicando qual o nível que cada criança participante da pesquisa se encontrava, uma vez que todas já utilizam o programa TEACCH no seu formato tradicional. Além disso, a única pessoa que pode intervir dentro do processo de execução da atividade foi o profissional que acompanha a criança, uma vez que já possui uma maior afinidade com a mesma, o que possibilitou ao usuário uma segurança para uma mudança da rotina que está habituado a executar.

A referida intervenção se limitou a apresentar o aplicativo à criança e a ajudar inicialmente aquelas que precisaram entender a dinâmica do aplicativo, uma vez que até mesmo o tablet era uma novidade para essas crianças. Outra forma de intervenção foi o direcionamento da atenção para a atividade, devido a algumas crianças apresentarem graves transtornos de atenção. Tal intervenção foi apenas para preservar o princípio da aprendizagem sem erro e, consequentemente, evitar frustrações frente aos mesmos. Durante os testes os avaliadores apenas observaram a execução das atividades por parte da criança e contabilizaram o número de erros e o tempo envolvidos dentro de cada execução, além de discutir com o profissional ao final de cada bateria de atividades quais as percepções que teve da criança durante a realização das atividades que acompanharam.

O processo de validação permitiu a análise de muitos requisitos, porém no presente estudo serão abordados apenas os resultados relacionados ao tempo de execução das atividades de cada nível bem como o número de erros por nível. Acredita-se que a explanação de tais dados seja suficiente, por hora, para atestar a efetividade da ferramenta desenvolvida.

A Figura 5 apresenta a média de tempo gasto pelas crianças de cada nível para concluir toda a bateria de atividades. Observa-se que apesar de ser no nível 4 que estão localizadas as tarefas consideradas mais difíceis para o aprendiz, o maior tempo gasto aconteceu nas atividades de nível 2 cuja média foi 237 segundos, enquanto que no nível 4 foi 189,6 segundos. Tal fato pode ter ocorrido porque no nível 2 começam a surgir atividades que requerem discriminação de elementos, cores e formas, enquanto que as crianças de nível 4 no programa TEACCH já apresentam uma capacidade cognitiva mais elevada, e mesmo com dificuldades iniciais do primeiro contato com o aplicativo, conseguem identificar a lógica nas atividades seguintes e passam a aprimorar o desempenho com o tempo.

A menor média de tempo foi verificada na execução das atividades de nível 3, pois são crianças que já conseguem identificar os elementos, formas e cores, e conseguem assimilar com facilidade a sequencia das atividades propostas. 


\section{Figura 5 - Gráfico do tempo médio de execução da sequência de atividades por nível TEACCH no ABC Autismo.}

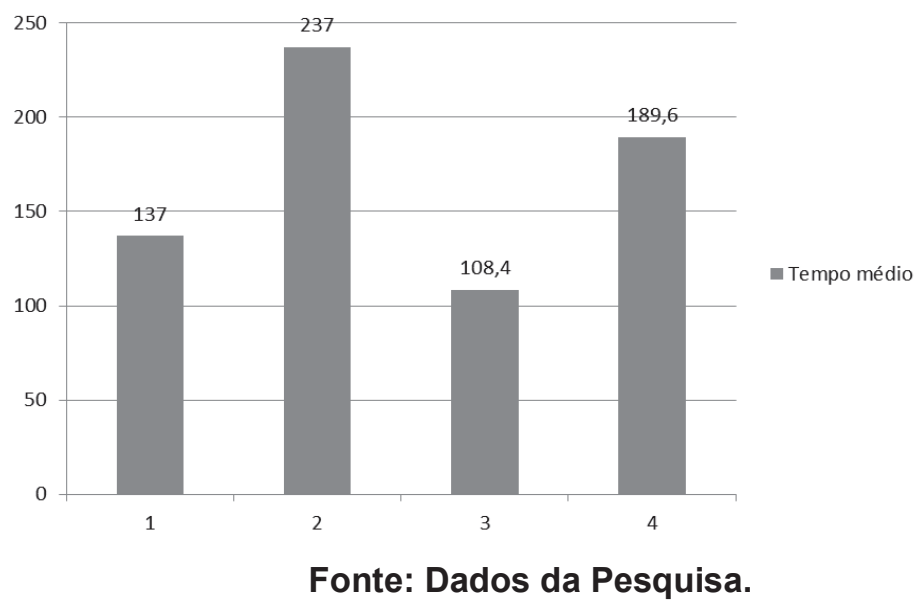

A Figura 6 apresenta a quantidade de erros total em cada nível de atividades. Como era de se esperar uma grande parcela aconteceu com as crianças que estão no nível 4 do programa TEACCH onde as atividades apresentavam um maior número de elementos e exigiam maior interpretação da proposta. $\mathrm{O}$ aplicativo apresenta um sistema que contabiliza os erros quando o usuário arrastar e soltar um elemento dentro da área que não é reservada para ele ou arrastar e soltar um elemento dentro da área que já foi preenchida.

Ao arrastar e soltar um elemento numa área qualquer da tela, que não seja a área de resposta, não é contabilizado erro pelo fato que algumas das crianças com autismo apresentam dificuldades na coordenação motora, e por vezes, acabam afastando o dedo da tela e o objeto com isso retorna para a posição inicial sem contabilizar acerto ou erro.

Com isso, analisando apenas o maior índice de erros, observa-se que o grupo de 09 crianças que estão no nível 4 do programa TEACCH, cometeram 79 erros, daí presume-se que o número médio de erros foi aproximadamente 9 por criança. Considerando que são 10 atividades em cada nível, pode-se dizer que a média de erros por atividade foi menor que 1, uma quantidade considerada mínima, que passa até despercebida, dado o desempenho geral das crianças.

Figura 6 - Gráfico do número total de erros por grupo de crianças que participaram da pesquisa de acordo com o nível TEACCH.

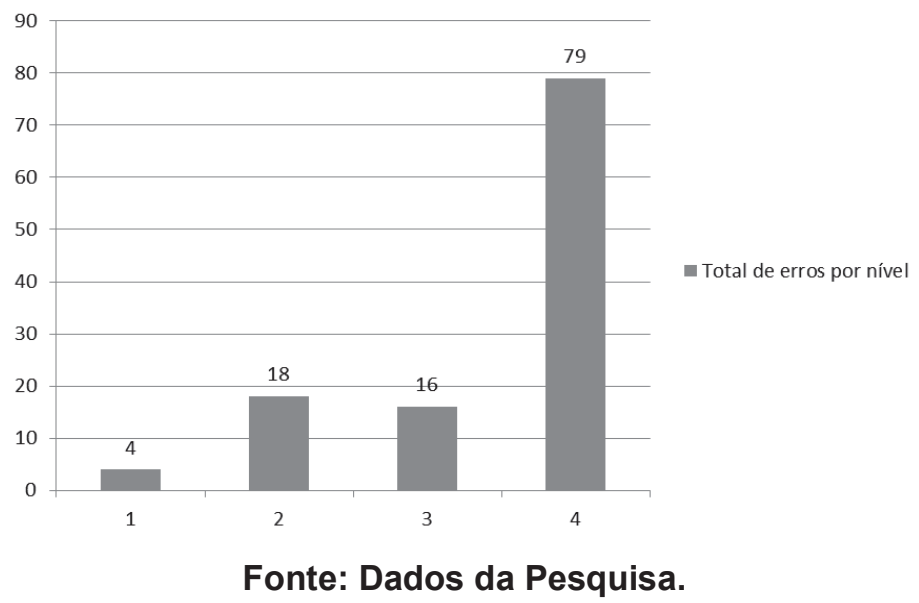




\section{CONCLUSÕES}

Os testes do aplicativo por parte do público-alvo e a receptividade dos pais e profissionais sobre o ABC Autismo indicaram que o mesmo pode agregar valor ao tratamento das crianças com autismo que, atualmente, nas escolas, associações e consultórios, não têm à sua disposição nenhum aparato tecnológico para ajudar no desenvolvimento de habilidades de leitura e escrita totalmente alinhado ao programa TEACCH. A atenção dedicada pelas crianças na execução de cada atividade do aplicativo animou toda a equipe que acompanhou os testes, revelando que as interfaces propostas ajudam a manter a criança focada na atividade e, consequentemente, contribuem para o aprendizado. As possibilidades abertas com o uso do aplicativo animaram a todos os envolvidos com o universo autista. De acordo com os profissionais, o uso da ferramenta proporcionará uma economia de tempo na elaboração e confecção das atividades para toda a equipe.

Para os pais o aplicativo representa uma nova "esperança" para um efetivo tratamento de seus filhos, pois muitos relataram que existem inúmeros aplicativos na internet que auxiliam a alfabetização, mas a maioria não está focada nos déficits de seus filhos, ou seja, não está voltada para pessoas com autismo. Ao se depararem com uma ferramenta que utiliza os princípios básicos do Programa TEACCH, prezando por uma adaptabilidade alfabetizadora, os pais se sentiram estimulados a auxiliarem seus filhos na utilização do aplicativo, inclusive fornecendo dicas de atividades voltadas para a exploração de potencialidades de seus filhos. Para os autistas o aplicativo representou um novo brinquedo, iterativo, divertido, onde poderão aprender prazerosamente com imagens e representações comuns ao seu dia a dia.

A dinâmica alfabetizadora utilizada no aplicativo está devidamente representada através de níveis de complexidade diversos, visando auxiliar a criança autista a aprender de uma forma adaptada às suas necessidades, por meio de uma estratégia a partir da qual as unidades básicas da leitura são ensinadas ao individuo, de acordo com as premissas do programa TEACCH.

Apesar do aplicativo não ter conseguindo uma unanimidade de satisfação entre as crianças, acredita-se que a possibilidade de adequação da sequência de atividades aos gostos de cada uma delas terá efeitos mais satisfatórios, uma vez que este recurso encontra-se potencializado dentro da dinâmica do aplicativo. É importante frisar que o intuito do aplicativo não é de substituir a intervenção atualmente utilizada com as crianças, pois os métodos tradicionais ajudam na adaptação social do indivíduo. A proposta apresentada no presente trabalho não pretende isolar a criança em mundo particular, livre de estímulos externos, mas sim complementar todas estas ações que compõem o tratamento, visando a gradual evolução do quadro do indivíduo além da ampliação do escopo de alcance dos benefícios interventivos.

Os resultados obtidos são animadores. Todas as funcionalidades pensadas para o aplicativo, o processo de prototipação dos modelos de tela com o posterior design dos elementos utilizados na interface foram fundamentais para a aceitação das crianças que utilizaram o aplicativo. A possibilidade da automatização de um processo que já se encontra internalizado pelas crianças representa um diferencial significativo dentro da dinâmica interventiva do tratamento, uma vez que futuramente fornecerá informações estatísticas que poderão ser utilizadas para um acompanhamento mais efetivo da evolução da criança e, quem sabe, auxiliar no diagnóstico do nível de comprometimento cognitivo da criança dentro da dinâmica TEACCH, aumentando ainda mais os benefícios advindos com a utilização do $\mathrm{ABC}$ Autismo. 


\section{REFERÊNCIAS}

CAPUCHA, L. Unidades de ensino estruturado para alunos com perturbações do espectro ao autismo - Normas orientadoras. Direcção-Geral de Inovação e de Desenvolvimento Curricular. Lisboa: MEC, 2008.

COELHO, M; ESPÍRITO SANTO, A. Necessidades Educativas Especiais de Carácter Permanente/ Prolongado no Contexto da Escola Inclusiva. 2006. CENFOCAL (Centro de Formação Contínua de Professores de Ourique), Castro Verde.

FARIAS, E. B.; CUNHA, M. X. C. Protótipo de uma Ferramenta de Software para Apoio no Tratamento de Crianças com Autismo. In: Simpósio Brasileiro de Sistemas de Informação, 9, 2013, João Pessoa - PB. Anais... João Pessoa: SBSI, 2013, pp 332-342.

GUPTA, A. R; STATE, M. W. Autismo: genética. Revista Brasileira Psiquiatria. V 28 (Supl I): S29-38. 2006.

ORRÚ, S. E. Autismo, linguagem e educação: interação social no cotidiano escolar. Rio de Janeiro: Wak Ed., 2009.

RAPIN, I. Autistic children: diagnosis and clinical features. Pediatrics. 1991;87:751-60.

SCHWARTZMAN, J. S; ARAÚJO, C. A. (Orgs.). Transtornos do espectro do autismo: Conceitos e generalidades. São Paulo: Memnon. p. 37-42. 2011.

SANTOS, R. P. R. A Linguagem em Crianças com Perturbações do Espectro do Autismo: Análise Morfossintáctica. Dissertação - Mestrado em Ciências da Fala e da Audição, Universidade de Aveiro. 2009. 